\title{
COMUNICAÇÃO INTERNA: PRIMÓRDIOS E ATUALIDADE
}

Thiago Massuia

Universidade do Oeste Paulista - UNOESTE. Presidente Prudente - SP.

\section{RESUMO}

Datado em 1960, os primeiros documentos que fazem referencia a Comunicação Organizacional já completaram mais de 50 anos. Atualmente, após décadas de desenvolvimento e resultados mensurados, esta atividade ganhou novo fôlego com o início de novos meios de comunicação, garantindo assim novas formas de disseminação da mensagem. O objetivo desta pesquisa foi analisar os conteúdos bibliográficos a fim de estabelecer de forma compreensiva as mudanças ocorridas nestes anos de atividade comunicacional voltada à organizações.

Palavras-chave: Comunicação Interna; Jornalismo Empresarial; Comunicação Empresarial

INTERNAL COMMUNICATION: BEGINNINGS UNTIL TODAY

\section{ABSTRACT}

Dated in 1960, the first documents that reference Organizational Communication has completed more than 50 years. After decades of development and measured results, this activity has gained new momentum with the onset of new media, ensuring new ways of spreading the message. The objective of this research was to analyze the bibliographic content in order to establish comprehensively the changes in these years of communication activity focused on organizations. Keywords: Internal Communications; Entrepreneurial Journalism; Business Communication 


\section{INTRODUÇÃO}

Muito se diz sobre a importância da Comunicação Empresarial e como ela deve conduzir e manter os valores e visão da empresa aliados aos do colaborador. Este desafio é atual, e teve início há algumas décadas, quando a comunicação interna tornou-se relevante e pode ser identificada nos processos da empresa como uma área a ser explorada.

Inicialmente, esta atividade sofreu preconceito por parte de quem não entendia a real necessidade de comunicadores ingressados no dia-a-dia empresarial. Cerca de 50 anos depois das primeiras menções a comunicação institucional no país, faz-se necessário avaliar as condições atuais desta estratégia.

Se bem dirigida e mantida, uma boa relação entre instituição e funcionário, gera melhorias para os dois lados.

Esse estudo teve como metodologia a pesquisa bibliográfica, que se mostrou mais adequada na busca da história a cerca da Comunicação Empresarial e mais especificamente da comunicação interna, e relatar de forma qualitativa baseada nas leituras de publicações desta área.

Assim essa pesquisa foi feita com o objetivo de apresentar um estudo aprofundado sobre a comunicação interna. Oferecendo ao leitor um panorama sobre o tema central deste artigo a partir de uma compilação de possibilidades para a aplicação desta atividade nos ambientes empresariais e traçar com a atual condição de trabalho e tendências se contrapondo a história referente ao exercício desta atividade no Brasil.

\section{COMUNICAÇÃO ORGANIZACIONAL}

\section{Os Primórdios}

A história da comunicação organizacional no Brasil se confunde com a história do desenvolvimento econômico, social e político nas últimas décadas. No fim da década de 60 , o conceito começava a fazer parte da rotina das empresas que iniciaram um processo de interlocução com públicos mais diversos.

Na década de 1990 a globalização propiciou uma maior abertura para a comunicação organizacional. Rego (2008, p. 8) lembra que neste momento os discursos empresariais se tornaram intensos e ecoavam de forma mais efetiva. Paralelamente a mídia especializada, passou a exigir novos comportamentos e atitudes por parte das empresas.

Nos anos 90, certos fenômenos se fizeram sentir de maneira intensa no Brasil. [...] Organizações não governamentais, disseminadas por todo o país, começaram a eleger bancadas parlamentares como a dos religiosos, a dos 
advogados, a dos policiais, a dos ruralistas. As ONGs, abrindo espaços, fortaleceram-se no meio da sociedade, ditando pautas para a mídia e expandindo influência junto aos poderes organizados. (REGO, 2008, p. 8)

Em relação a este novo mercado que começava a se estruturar, as Relações Públicas definia os espaços internos para a execução dos programas de comunicação que concentravam-se prioritariamente na área externa, planejando e operando as estratégias de projeção de imagem.

Segundo Rego (2008, p. 4) no final da década de 1970 o modelo de comunicação dentro das empresas foi alterado:

No final da década de 1970, no âmbito das organizações, percebia-se ênfase aos valores do associativismo e da solidariedade, a maneira de fomentar o clima interno. A função da comunicação como alavanca de mobilização aparecia como eixo de estratégia de arregimentação dos trabalhadores em torno da meta de dar o melhor de si à organização. Os primeiros modelos corporativos começaram a surgir. (REGO, 2008, p. 4)

Desta forma a comunicação dentro das empresas ganha força de maneira acelerada e o público interno das corporações se desataca como um importante público a ser atingido a fim de otimizar o trabalho dentro das organizações.

\section{Jornalismo Empresarial}

O termo Jornalismo Empresarial passou a ser empregado por ter os conceitos básicos desta atividade, aplicadas na empresa. As informações geradas pela organização devem ser tratadas como notícias de fato, e publicadas de acordo com as técnicas jornalísticas. Torquato (2002, p. 70) lembra que as publicações que as publicações veiculadas como notícia devem ter periodicidade. 0 autor explica que "Ter periodicidade, isto é, devem aparecer em intervalos sucessivos e regulares. Precisam investir-se dos fatos da atualidade, que formam o presente da empresa."

\section{Comunicação Externa}

$\mathrm{Na}$ área da comunicação externa, se trabalha o posicionamento da marca, a imagem com que ela é vista pela sociedade.

Nesse processo se incluem toda a veiculação de informações e todos os comunicadores emitidos pela organização empresarial para um público ou uma opinião pública fora dos limites internos. Em geral, o uso que a empresa faz dos meios de comunicação para o fim de tornar conhecidas as suas mensagens. (BAHIA, 1995, p. 33) 
Nesta ótica, a empresa deve privilegiar, além do público específico, os setores difusos da sociedade, como consumidores que estão nos setores sociais de interesse aos quais as ações institucionais são dirigidas. (BAHIA, 1995, p. 34)

\section{Comunicação Interna}

A Comunicação Interna está inserida no campo em que se dá a Comunicação Social, que segundo Torquato (2002, p. 52), possui a função de disseminar a informação tanto no âmbito interno, quanto no campo externo. De acordo com Estrella e Fernandez (2009, p. 127), a Comunicação Interna se dá com o público conhecido, ou seja, os funcionários que assumem uma relação de trabalho com a instituição.

Mais importante do que na comunicação em geral, a definição do público alvo é de extrema importância para o sucesso da comunicação. A Comunicação Interna deve ter como um dos objetivos, auxiliar o departamento de Recursos Humanos na troca de informações no que se diz respeito ao humor dos trabalhadores. E para isto é preciso diagnosticar com razoável grau de acerto, as causas das insatisfações, angústias, frustrações, tensões e ansiedades que nascem, com intensidade, no ambiente interno da organização. (NEVES, 2003, p. 315)

“A mídia adequada à mensagem é metade do sucesso na comunicação. Relembrando o recado de McLuhan, "O Meio é a Mensagem". Isto quer dizer que a forma usada para a comunicação já é a comunicação em si." (NEVES, 2003, p. 343)

Através deste meio, com a aplicação de técnicas jornalísticas, a empresa pretende atingir alguns objetivos:

[...] fazer informar seu público de interesse, engajar esse público em suas atividades e mensagens preferenciais, implementar e manter vias de agenciamento comunicativo com esse público e avaliar continuamente os níveis de interferência que as atividades da empresa geram no clima organizacional ao criar condições e instrumentos que podem ser utilizados diante das mais variadas demandas [...] (ESTRELLA; FERNANDEZ, 2009, p. 132).

Dessa forma, quanto mais trabalhado estiver o clima organizacional, melhor será a propagação positiva da reputação institucional. Isso porque os colaboradores são 'a cara' da empresa, e funcionários motivados oferecem melhor desempenho ao lidar diretamente com a sociedade.

REGO (2008) explica que a eficácia ou ineficácia das comunicações depende de um conjunto de fatores. O primeiro fator diz respeito às atitudes. "Este fator pode ser dividido em 
três partes: atitude para consigo; atitude para com o assunto e atitudes para com o receptor." (NEVES, 2008 p. 36)

\section{Ferramentas de Comunicação Interna}

As ações de comunicação interna se dão através de veículos de comunicação que podem variar de organização para organização. "São formas, instrumentos ou veículos de comunicação interna: a assessoria de imprensa ou de comunicação; os produtos (jornal, revista, [...]) que a empresa edita para distribuição interna; os boletins informativos [...]." (BAHIA, 1995, p. 18)

A escolha dos canais está diretamente associada ao porte da organização, à dimensão espacial de suas unidades, aos tipos de público que se quer atingir e à periodicidade das mensagens. O planejamento estratégico da comunicação obrigatoriamente levará em conta o tipo dos canais jornalísticos e sua integração aos canais das comunicações gerenciais e administrativas. (REGO, 2008, p.58). Através destes canais de comunicação, o objetivo é aumentar a participação dos funcionários, integra-los e disseminar as informações institucionais.

\section{A Comunicação Interna atual}

Mais de 50 anos após as primeiras impressões documentadas de Comunicação Interna no Brasil, a realidade deste instrumento para a disseminação de informações e valores organizacionais possui características muito distintas das vistas no início desta atividade.

As mídias digitais têm espaço garantido e utilização essencial para que a devida comunicação entre empregador e empregado se dê. Outro fator relevante, é o investimento aplicado a esta área, que não chega a ser o ideal, porém, atualmente a comunicação empresarial tem sido apreciada pelos resultados alcançados.

Desta maneira, Clemen $(2005$, p. 64) os canais de comunicações digitais ganham cada vez mais espaços nas Empresas. $\mathrm{O}$ autor lembra que $\mathrm{o}$ a agilidade que essas mídias proporcionam: "São de grande utilidade para fortalecer o fluxo da Comunicação Interna, principalmente com o nível gerencial cada vez mais ocupado com atividades e responsabilidades." (CLEMEN, 2005, p. 64)

\section{DISCUSSÃO}

Baseado no estudo que resultou a produção deste artigo o autor se propõe a destacar o papel da comunicação no âmbito empresarial. Em destaque a comunicação a comunicação institucional interna que ganha este valor pois é capaz de estabelecer uma relação de troca, comprometimento e de engajamento entre empresários e colaboradores. Nesta perspectiva, a 
atual tendência para o mundo corporativo é a relação colaborativa, que deixou de ser pensada como a de ordem e execução, como a história demonstra. Colaboradores fazem parte de um processo de via de mão dupla, que ganham por vestirem a camisa da organização da qual fazem parte.

Desta forma as iniciativas dentro das organizações ficarão muito mais propensas a alcançar efeitos positivos sobre o público em questão. É possível destacar a possibilidade, por exemplo, de fortalecer um clima interno favorável, direcionar ações, despertar a produtividade e motivação dos empregados, e construir uma imagem positiva, perante seu quadro de funcionários.

\section{CONSIDERAÇÕES}

Tendo como referência básica os autores deste artigo buscam salientar a importância da comunicação no âmbito empresarial. Em destaque a comunicação a comunicação institucional interna que também foi beneficiada com o avanço da tecnologia e em especial a evolução e massificação da internet. Todavia, junto com a mudança positiva para os profissionais de comunicação empresarial nasceram também outras problemáticas que devem ser levadas em consideração pelo responsável pela comunicação.

Além da linguagem que deve ser levada em consideração, a escolha do canal de veiculação quando usada de forma inadequada perde a força. O responsável pela comunicação deve tomar cuidado ao usar a internet, por exemplo, para veicular determinada mensagem. Neste patamar é necessário fazer questionamentos em relação ao público alvo da mensagem. Neste caso é necessário ter certeza que as pessoas que devem ser atingidas com a mensagem tenham acesso a computadores.

Por fim procuramos evidenciar a importância da comunicação interna e destacar o papel dela aliada a internet e as novas ferramentas que ela proporciona aos profissionais da comunicação. É importante destacar também a necessidade continua de atualização por parte das empresas.

\section{REFERÊNCIAS}

BAHIA, Juarez. Introdução à Comunicação Empresarial. Rio de Janeiro: Mauad, 1995.

CLEMEN, Paulo. Como implantar uma área de comunicação interna. Rio de Janeiro: Mauad, 2005.

FORT, Mônica Cristine et al. Comunicação face a face: o que se vê e o que não se vê no relacionamento interpessoal nas organizações. In: ESTRELLA, Chaberlly; BEVENIDES, Ricardo; 
FERREIRA FREITAS, Ricardo. Por dentro da Comunicação Interna: tendências, reflexões e ferramentas. 2009

NEVES, Roberto. Imagem Empresarial: Como as organizações (e as pessoas) podem proteger e tirar partido do seu maior patrimônio. Rio de Janeiro: Mauad, 2003

REGO, Francisco Gaudêncio Torquato do. Tratado de Comunicação organizacional e política. São Paulo: Cengage Learning, 2008.

TORQUATO, Gaudêncio. Tratado de Comunicação organizacional e política. São Paulo: Cengage Learning, 2002. 